\title{
Over Current Protection Relay using Arduino Uno for Future Renewable Electric Energy Delivery and Management (FREEDM) System
}

\author{
Mohamed. F. Kotb, Magdi El-Saadawi, and Eman H. El-Desouky
}

\begin{abstract}
The FREEDM (Future Renewable Electric Energy Delivery and Management) system is a smart grid that enables wide integration between the Distributed Renewable Energy Resources (DRER) and Distributed Energy Storage Devices (DESD) with the conventional distribution system. This paper presents the design and implementation of an Arduino Uno microcontroller-based overcurrent relay with different characteristics (inverse, very inverse and extremely inverse) for FREEDM systems. An open source model with simple utilization of both hardware and software is created. A practical printed circuit board is designed with the required inputs and outputs to monitor and protect the branch connecting solid state transformer (SST) to the closed loop zones in the FREEDM system. A special program is designed using Proteus software package and easily integrated to the hardware card. To validate the proposed relay, the inverse, very inverse and extremely inverse overcurrent relay characteristics are tested using the proposed system simulator and compared with the characteristic recorded by the wellknown IEC 60255-151standard. In order to guarantee the effectiveness of the system, a practical circuit including the proposed relay is formed, connected to a small load (motor) and normally inverse relay characteristic is tested. The proposed protection scheme proves high performance and accurate results.
\end{abstract}

Index Terms-FREEDM; Overcurrent Relay; Arduino Uno Controller; Proteus Software.

\section{INTRODUCTION}

In 2008, the National Science Foundation (NSF) has formed a new smart grid networks supported with innovative facilities called FREEDM system to integrate the green DRERs, DESD's and the conventional power systems. The new networks form leads to best utilization of stored energy and high system reliability [1]-[3]. The major components of FREEDM system are shown in Fig. 1 [2]. Fault Isolation Device (FID), intelligent fault detection (IFD) and Solid-State Transformers (SST) are the three new major equipment in FRREDM system which improves the network protection and power quality. The major advantage of the three equipment is they are static elements controlled by digital control instead of the conventional equipment. SSTs are solid state thyristors or certain type of transistors

Published on August 31, 2018.

M. F. Kotb is with the Department of Electrical Engineering, Faculty of Engineering, Mansoura University, 35516 Mansoura, Egypt (e-mail: mohamadfawzi@gmail.com)

M. El-Saadawi is with the Department of Electrical Engineering, Faculty of Engineering, Mansoura University, 35516 Mansoura, Egypt (e-mail: m_saadawi@mans.edu.eg)

E. H. El-Desouky is with the North Delta Electricity Distribution Co. Mansoura (Egypt) (e-mail: Eman.el desouky@ yahoo.com) controlled by digital signals instead of normal electromagnetic transformers. In addition to controlling voltage and phase angle with current, it allows the power to flow in both directions. It has the ability to limit the fault current to 2.0 p.u. by reducing the voltage [3]-[5]. FID is a new static equipment used to break and isolate high values of asymmetrical fault currents within microseconds instead of normal electromechanical circuit breakers which take milliseconds [2], [5]. Intelligent energy management (IEM) and intelligent fault detection (IFD) control schemes are combined in the FREEDM system to achieve effective power flow, fast fault detection and management [4].

The FREEDM closed loop leads to high short circuit levels, voltage dip and of power flow in two directions [2]. Pilot-differential protection using communication is used as primary protection capable to detect the faults in cycles whereas, overcurrent protection is used as a backup protection in case of communication problems/failures, [1][2]. Directional inverse time overcurrent relays are applied to detect the fault in the system as in [2], [6].

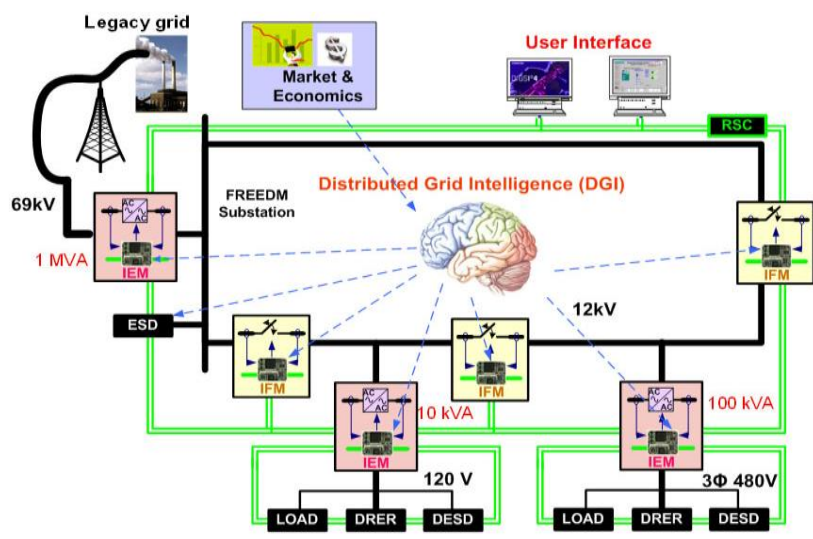

Fig. 1. FREEDM system topology and components [2]

The overcurrent relays generations started with conventional electromechanical relays followed by static and digital relays. The last two generations prevent the overshooting errors and reduces time delay. Nowadays, microprocessor and microcontroller relays are introduced to eliminate their disadvantages. This leads to enhance power system protection; better reliability, reducing the impact on the electric power system equipment and facilitate power system automation. Microcontrollers deal with low voltage and current inputs and have good stability to the current variations. They contain RAM, ROM and other peripherals while microprocessors have only CPU [7]. In literature, Arduino Uno microcontroller was utilized for overvoltage and overcurrent protection of simple single phase-two 
terminal systems in [8] and for transformer protection in [7]. Differential protection of transformer technique was proposed using Arduino with GSM and voice circuit in [9]. The authors recommended to use Arduino in place of 8051 microprocessor as it is a low cost-effective device with very high speed and fine accuracy. A protective strategy was applied using Arduino controller to senses temperature and current and trip load at preset values [10]. Transformer differential protection was employed using Arduino in [11][13]. The Arduino senses the condition of transformer each and every second. If it founds any error, then it sends commands to the circuit breakers to trip the main potential transformer. Finally, Arduino was utilized to monitor and protect motors against overvoltage, over-current, overload, excessive heating, crawling and under-voltage [14]. A Proposed software was introduced and fed by the real time data of the power system using Arduino in [15]. The software was used to recognize and indicate different types of fault conditions based on pre-set values, and then disconnected the load side.

In this paper an Arduino Uno microcontroller-based overcurrent relay with different characteristics (inverse, very inverse and extremely inverse) is designed for FREEDM systems. A Software simulator and a hardware circuit are designed and implemented. The designed practical printed circuit board is equipped with the required inputs and outputs as for the FREEDM system. A friendly program is created using Proteus software package and easily integrated to the hardware card. Different scenarios are applied to the simulator to satisfy the three types of overcurrent relay characteristics and the results are compared with the characteristics recorded by IEC 60255-151standard [16]. The normally inverse relay characteristics is tested and fulfilled using the practical circuit.

\section{PRoblem STATEMENT}

Overcurrent protection is very important to protect the branch connecting SST to the closed loop zones in the FREEDM system as shown in Fig. 2. The distribution bus may import the power from the medium voltage loop to the loads beside the local generation in case that the local generation power is lesser than the connected loads. Similarly, it may export power to the medium voltage loop in case that the local power is larger than the connected loads. The management of electric loads is activated by DGI (Digital Grid Intelligent) of the FREEDM unit. The SST is always a pi direction to perform the function of IEM. For these reasons, the overcurrent relay should be installed in the link between SST and the loop of FREEDM as shown in Fig. 2.

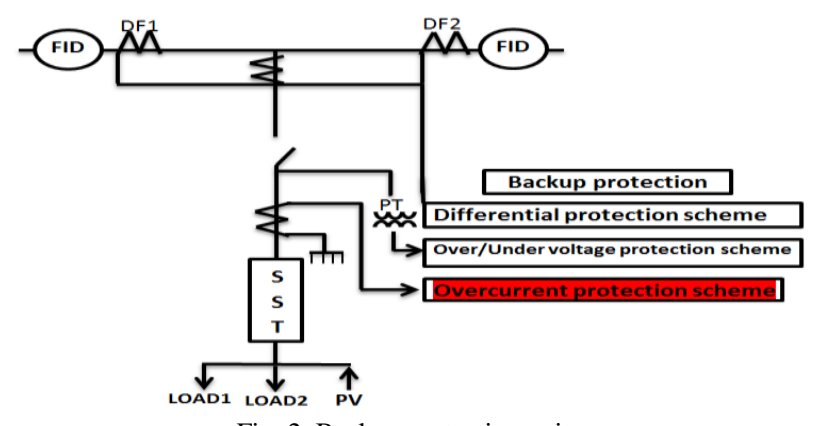

Fig. 2. Backup protection units

The backup protection unit of FREEDM system consists of three main protection schemes, overcurrent, over/under voltage, and differential protection schemes, as explained by Fig. [2]. In this paper, a new design of an overcurrent relay using Arduino microcontroller is introduced. The proposed design has a very low cost, high speed and fine accuracy. The used Arduino microcontroller is quite efficient and easy for programming. The results, obtained from the proposed O.C relay are compared with the values obtained by the standard IEC characteristic curves in the three modes of operation (normal, very invers, extremely) and proofed very little errors.

\section{PROPOSED TECHNIQUE}

Overcurrent protection scheme is proposed as per the block diagram shown in Fig. 3 and flow chart in Fig. 4. Hardware Arduino microcontroller is utilized by downloading software program designed through Proteus package using $\mathrm{C}$ language. A software is created to satisfy different overcurrent relay characteristics (invers, very inverse and extremely inverse) which are required to protect FREEDM system. The followed standard characteristics is simulated in the program as per the following equations:

$$
\begin{aligned}
& T=\frac{K 1}{\left((M)^{K 2}\right)-1} * T D S \\
& M=\frac{I_{f}}{I_{\text {pickup }}}
\end{aligned}
$$

where: $\boldsymbol{T}$ : Relay Operating Time, $\boldsymbol{I}_{\boldsymbol{f}} \quad$ : Fault current value, $\boldsymbol{I}_{\text {pickup }}$ : Pickup (set start) current value, $\boldsymbol{M}$ : Current Multiplier, $\boldsymbol{K}_{\mathbf{1}}, \boldsymbol{K}_{\mathbf{2}}$ : Curve set-related parameters (inverse, very inverse, extremely inverse, etc..)

The value of current flows from supply to the load is sensed by hall effect current transformer. The current signal is converted to dc voltage using shunt resistance to suite the microcontroller requirements. The produced voltage signal which is proportional to this current value is fed to Arduino Uno microcontroller. The voltage signal is varied based on the actual current value in the main circuit. If value of current exceeds the pre-set value, an output signal is generated to trip the solid-state switch to disconnect the load and to display the fault current on the LCD. 


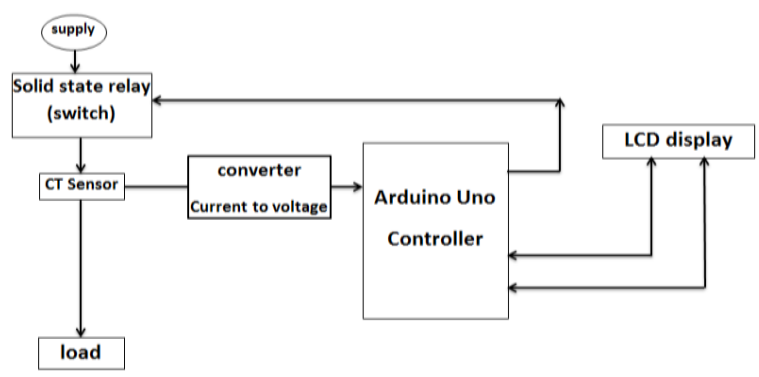

(a) block diagram of overcurrent relay

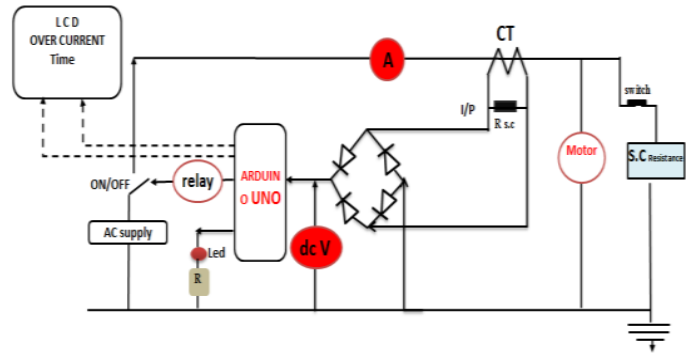

(b) Circuit diagram

Fig. 3. Proposed overcurrent relay using Arduino Uno controller

The process of the proposed technique is displayed as the flowchart in Fig. 4 and can be summarized as following:

1) Select the values of $\mathrm{K} 1, \mathrm{~K} 2$ according to the required mode of operation by adjusting resistance R1.

2) Select the value of Time Dial Setting "TDS" using variable resistance R2.

3) Apply short circuit across the load. Short circuit value is varied by using variable resistance parallel with the load.

4) Calculate $\mathrm{M}$ multiplier using (2) and identify operating time using (1).

5) Derive characteristic curves for different modes using the corresponding values of $\mathrm{M}$ and $\mathrm{T}$.

6) Compare the characteristic curves for different modes with the standard characteristics of IEC for certain TDS.

\section{Circuit DESIGN}

The main components of the prototype circuit diagram indicated in Fig. 5 can be summarized as following:

1) Arduino Uno microcontroller

2) Hall effect current transformer ACS712

3) Solid state relay

4) LCD

\section{A. Arduino Uno microcontroller}

It is an open source platform, consists of two main parts; the first is a physical programmable circuit board that referred to as microcontroller, and the second part is a software that runs on a personal computer. Protus package is utilized to write the required program using $\mathrm{C}$-code software and up load program code to the physical board. The proposed microcontroller specifications are tabulated in Table I, Fig. 6 and Table II. These components which fully support the microcontroller, enables connecting to a computer with USB cable or supply it with AC-TO- DC adapter to get started.

TABLE I: ARDUINO UNO SPECIFICATIONS

\begin{tabular}{ll}
\hline \hline Item Name & Number \\
\hline
\end{tabular}

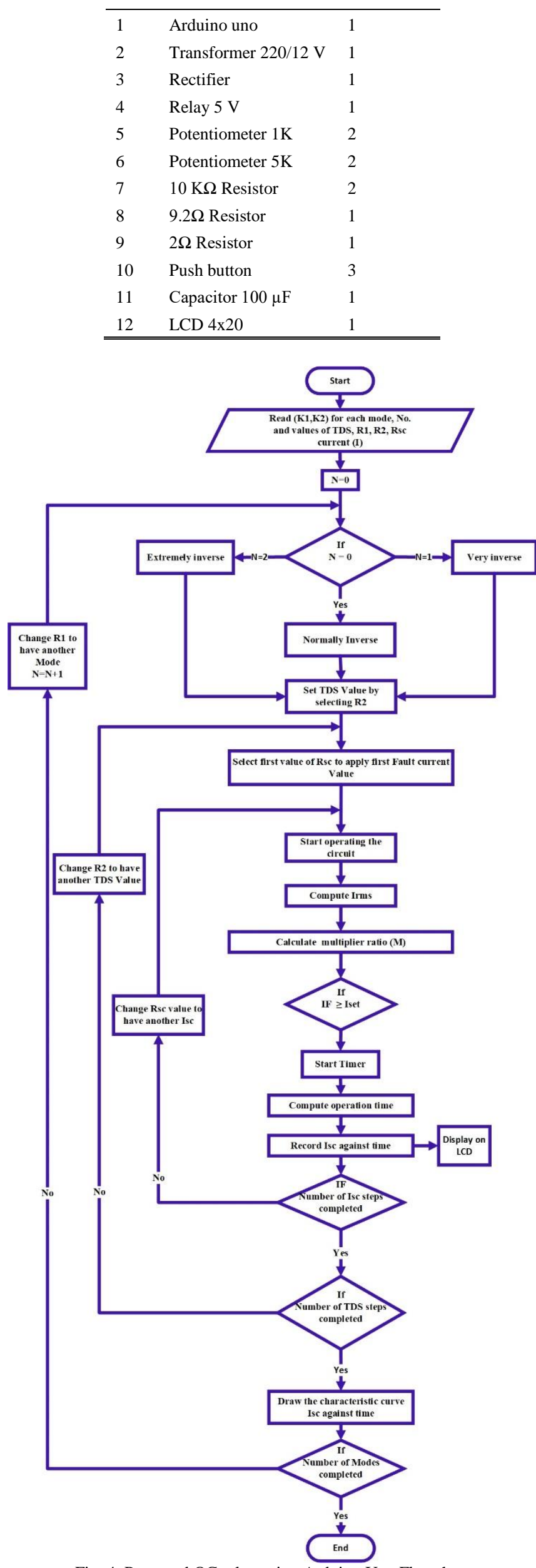

Fig. 4. Proposed OC relay using Arduino Uno Flowchart 


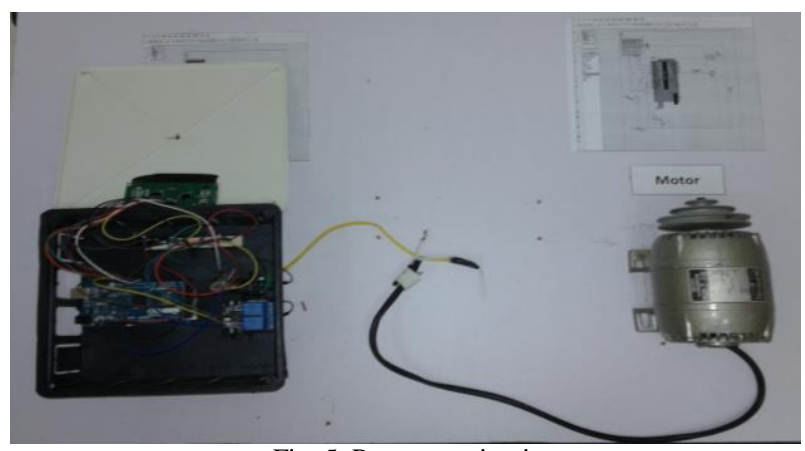

Fig. 5. Prototype circuit

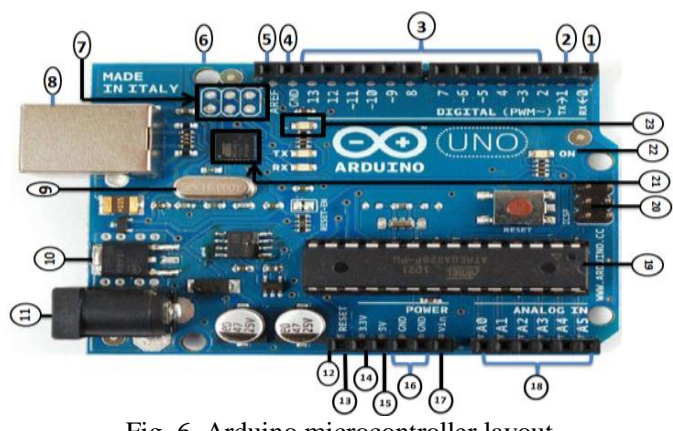

Fig. 6. Arduino microcontroller layout

TABLE II: ARDUINO MICROCONTROLLER COMPONENTS

\begin{tabular}{|c|c|c|}
\hline No & NAME & PIN DESCRIPTION \\
\hline 1 & Serial output (TX) & \\
\hline 2 & Serial input $(\mathrm{RX})$ & \\
\hline 3 & $\begin{array}{l}\text { Digital input/output } \\
\text { pins }(2-13)\end{array}$ & $\begin{array}{l}\text { The input/output voltage to the Arduino } \\
\text { Uno board when it is using an external } \\
\text { power source }\end{array}$ \\
\hline 4 & GND & Ground pin for digital \\
\hline 5 & AREF pin & $\begin{array}{l}\text { reference voltage for the analog inputs. } \\
\text { Used with analog reference }\end{array}$ \\
\hline 6 & Reset button & $\begin{array}{l}\text { Move this line low to reset the } \\
\text { microcontroller, and use to add a reset } \\
\text { button to shields which block the one on } \\
\text { the board }\end{array}$ \\
\hline 7 & $\begin{array}{l}\text { ICSP for AT mega } \\
16 \mathrm{U} 2\end{array}$ & \\
\hline 8 & USP plug & \\
\hline 9 & $\begin{array}{l}\text { AT mega } 16 \mathrm{U} 2 \\
\text { microcontroller }\end{array}$ & Memory \\
\hline 10 & Voltage Regulator & Regulate the voltage to $5 \mathrm{~V}$ \\
\hline 11 & $\begin{array}{l}\text { External power } \\
\text { supply plug }\end{array}$ & $\begin{array}{l}\text { Can supply voltage through it by the power } \\
\text { jack }\end{array}$ \\
\hline 12 & IOREF pin & $\begin{array}{l}\text { Provides the voltage reference with which } \\
\text { the microcontroller operates }\end{array}$ \\
\hline 13 & Reset pin & $\begin{array}{l}\text { Bring this line low to reset the } \\
\text { microcontroller }\end{array}$ \\
\hline 14 & $3.3 \mathrm{~V}$ pin & $\begin{array}{l}3.3 \mathrm{~V} \text { supply generated by the board } \\
\text { regulator. } \\
\text { Maximum current on the board } 50 \mathrm{~mA}\end{array}$ \\
\hline 15 & $5 \mathrm{~V}$ pin & The outputs $5 \mathrm{~V}$ on the board \\
\hline 16 & GND & Ground pins for analog \\
\hline 17 & Voltage in pin & $\begin{array}{l}\text { The VIN pin of board (7-12V) supply } \\
\text { voltage via } 5 \mathrm{~V} \text { or } 3.3 \mathrm{~V}\end{array}$ \\
\hline 18 & $\begin{array}{l}\text { Analog inputs } \\
\text { pins }(0-5)\end{array}$ & Read the analog data \\
\hline 19 & $\begin{array}{l}\text { AT mega } 328 \\
\text { microcontroller }\end{array}$ & Memory has $32 \mathrm{~KB}$ \\
\hline 20 & $\begin{array}{l}\text { ICSP for AT mega } \\
328\end{array}$ & \\
\hline 21 & TX, RX Led & \\
\hline 22 & $\begin{array}{l}\text { Power LED } \\
\text { indicator }\end{array}$ & \\
\hline 23 & On-Board LED & \\
\hline 24 & $\begin{array}{l}\text { ICSP for AT mega } \\
\text { 16U2 }\end{array}$ & \\
\hline
\end{tabular}

\section{B. Hall effect current transformer ACS712}

Microprocessors used for any protection scheme requires sensors which are considered a major element. Sensors convert the real time data into digital variable data in order to be processed by microprocessor. The ACS 712 sensor provides economical precise solution for AC or DC current sensing in industrial and communication system e.g motor control center, switching mode power suppliers, load detection and protection systems. The current transformer ACS712 shown in Fig. 7 consists of an accurate low effect linear Hall sensor circuit with copper conduction path located near the surface of the die. Applied current flowing through this copper conduction path generates a magnetic field which is sensed by the integrated Hall IC and converted into a proportional voltage. A precise proportional voltage is provided by the low effect. Upon the load variations, the $\mathrm{CT}$ output will be positive whenever an increasing in current flows in the primary copper conduction (from pin1 and 2 to pin 3 and 4) "current sensing path" as seen in Fig. 7.

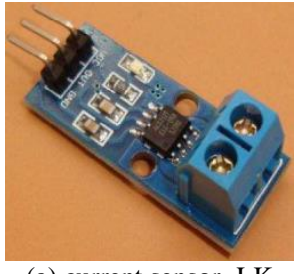

(a) current sensor- LK

Number Name of pin

$1 \& 2 \quad \mathrm{IP}+$

$3 \& 4 \quad$ IP-

5 GND

$6 \quad$ FILTER

VCC
$7 \quad$ VOUT

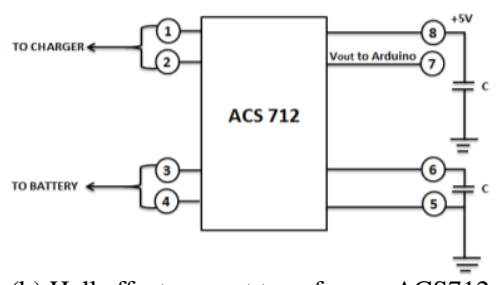

(b) Hall effect current transformer ACS712

Description

Input pins for current from supply

Input pins for current to battery

Ground signal terminal

Pin to external capacitor to control the bandwidth

Analog Output signal

Power supply volte

Fig. 7. Current sensor- and Hall effect current transformer ACS712

\section{Solid state relay}

A solid-state relay (SSR) is an electronic on/off switching device that initiated when a small external voltage is applied across its control terminals. It consists of a sensor which responds to an appropriate control signal, a are faster and more accurate than most mechanical relays. They can be switched by a lower voltage and they have much less sensitive to storage and operating environment factors such solid-state electronic switching device which switches power to the load circuitry, and a coupling mechanism to enable the control signal to activate this switch without mechanical parts. SSRs have many advantages over electromechanical relays. They as mechanical shock, vibration, and external magnetic fields. In this study, 5V-dc-2 channel relay module for Arduino Uno controller is used and can be controlled directly with $3.3 \mathrm{~V}$ or $5 \mathrm{~V}$.

\section{Liquid crystal display ( $L C D)$}

This device is a very important element in any electronic circuit. It displays the values of variables required for the user. LCD has 16 pins where the most left one is the ground pin and the second pin is the VCC connected to 5 volts on the Arduino board. Fig. 8 shows the other pins and their functions. 


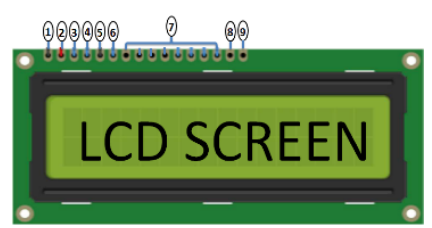

(a)

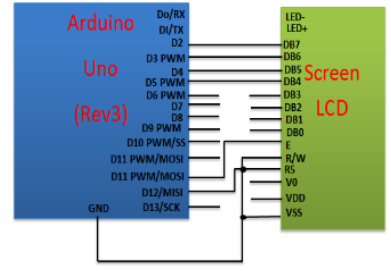

(b)
1: GND (ground); 2: VCC (5 volt); 3: VO (display contrast)

4: RS (register select); 5: R/W (read/ write); 7: D0-DD7(data pins)

8: A(anode) 9: K(cathode);

Fig. 8. liquid crystal display (LCD)

\section{Proposed Circuit Simulation ANd Results}

Three scenarios are simulated for inverse, very inverse and extremely inverse overcurrent relay characteristics at different TDS values.

\section{A. Scenario-1: Proposed normally inverse overcurrent} relay simulation

The procedure used to apply this scenario can be summarized in the following steps:

1) Select normal inverse overcurrent relay using the mode push button shown in Fig. 3 and Fig. 9,

2) Select TDS equal 0.05 by using TDS push button,

3) Use different values of the variable short circuit resistance R4 to change the fault current IF.

4) Obtain different values of both fault current and operating times according to the values of R4

5) Calculate the multiplier values for the chosen values.

6) Draw the proposed normally inverse relay characteristics as in Fig. 10.

7) Apply the same values of multipliers to the normally inverse relays specified in IEC 60255-151 and compare its characteristic against the proposed one as in Fig. 10.

8) Calculate the percentage error for each value as tabulated in Table III.

It can be noticed that the proposed extremely inverse overcurrent relay characteristic is nearly coincide with the same resulted from IEC standard as shown by Fig. 10. Very small errors are realized as illustrated by Table III.

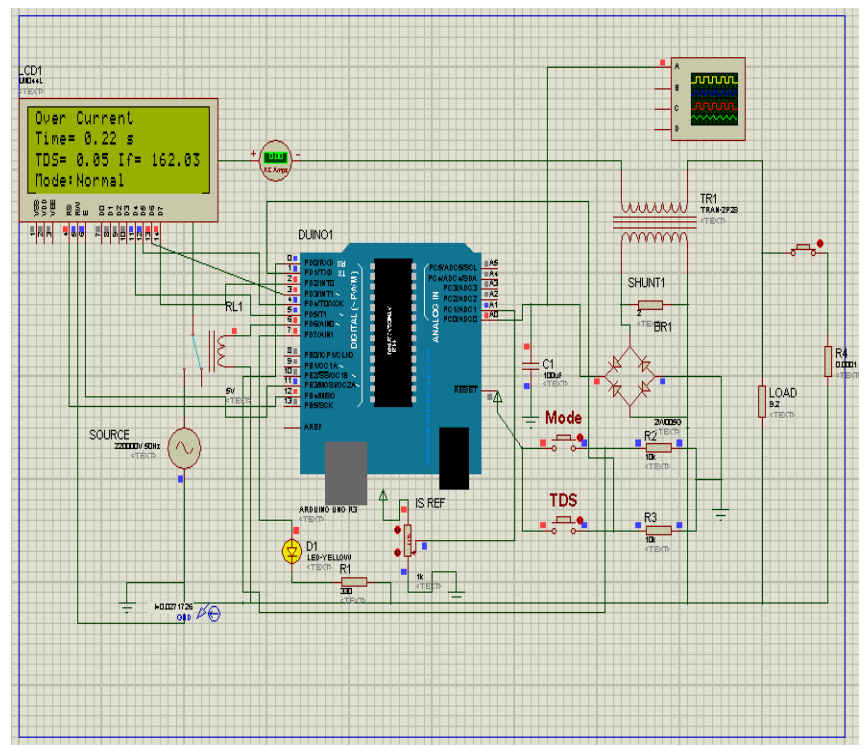

Fig. 9. Typical schematic diagram for Scenario 1 with TDS $=0.05$
TABLE III: NORMALLY INVERSE OVERCURRENT RELAY CHARACTERISTIC RESULTS AT TDS $=0.05$

\begin{tabular}{lllll}
\hline \hline $\boldsymbol{I}_{\boldsymbol{f}}(\mathrm{A})$ & 53 & 70 & 107 & 162 \\
\hline $\boldsymbol{I}_{\text {pickup }}(\mathrm{A})$ & 33 & 33 & 33 & 33 \\
\hline $\boldsymbol{M}=\frac{\boldsymbol{I}_{\boldsymbol{f}}}{\boldsymbol{I}_{\text {pickup }}}$ & 1.61 & 2.21 & 3.24 & 4.91 \\
\hline $\begin{array}{l}\text { (Sec) } \\
\text { Operating time as per Arduino }\end{array}$ & 0.71 & 0.46 & 0.29 & 0.22 \\
\hline Operating time as per IEC (Sec) & 0.72 & 0.47 & 0.3 & 0.23 \\
\hline \% Error & 0.01 & 0.02 & 0.03 & 0.04 \\
\hline \hline
\end{tabular}

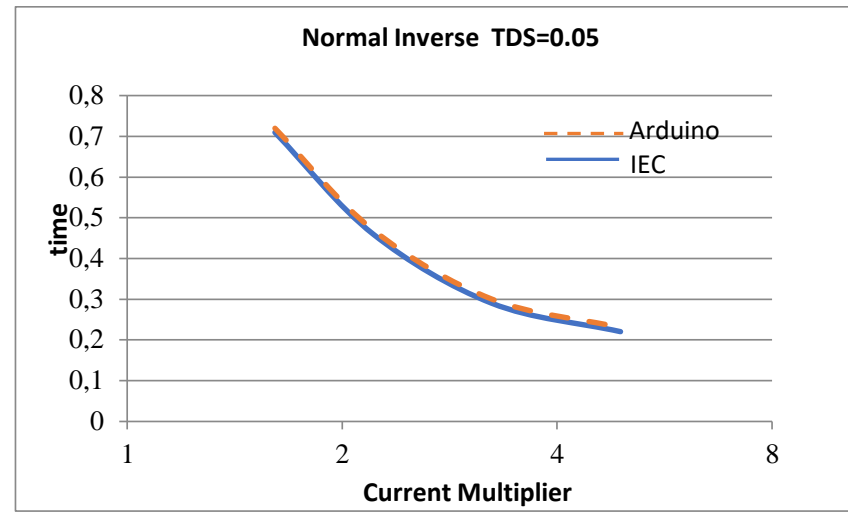

Fig. 10. Proposed normally inverse overcurrent relay characteristic at TDS $=0.05$ compared with IEC standard using simulator

\section{B. Scenario-2: Proposed very inverse overcurrent relay simulation}

The second mode "very invers " can be obtained by changing the mode push button. The typical schematic diagram of this mode is shown in Fig. 11. The same steps used in scenario 1 are repeated and the obtained very inverse overcurrent relay characteristic values are tabulated in Table IV and drawn in Fig. 12. The percentage error for each short circuit value is calculated and tabulated in Table IV. It can be noticed that the proposed very inverse overcurrent relay characteristic is nearly matched with the characteristic resulted from IEC standard and very small error is realized.

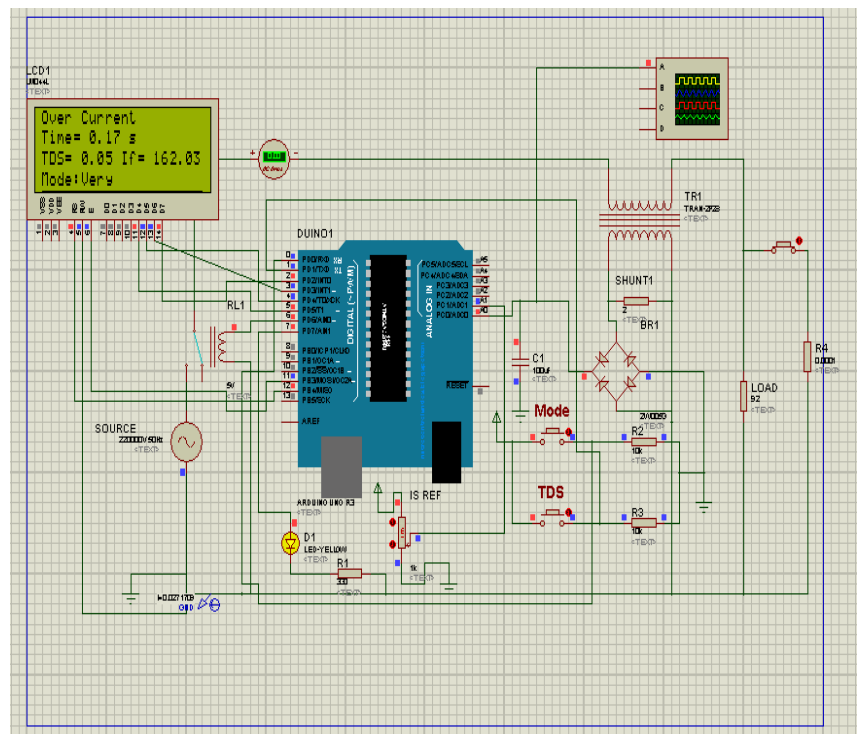

Fig. 11: Typical schematic diagram for Scenario 2 with TDS $=0.05$

TABLE IV: VERY INVERSE OVERCURRENT RELAY CHARACTERISTIC RESULTS AT TDS $=0.05$

\begin{tabular}{cccccc}
\hline \hline \multicolumn{2}{c}{$\boldsymbol{I}_{\boldsymbol{f}}(\mathrm{A})$} & 53 & 70 & 107 & 162 \\
\hline $\boldsymbol{I}_{\text {pickup }}$ & $(\mathrm{A})$ & 33 & 33 & 33 & 33 \\
\hline \hline
\end{tabular}




\begin{tabular}{ccccc}
\hline \hline $\boldsymbol{M}=\frac{\boldsymbol{I}_{\boldsymbol{f}}}{\boldsymbol{I}_{\text {pickup }}}$ & 1.61 & 2.21 & 3.24 & 4.91 \\
\hline $\begin{array}{c}\boldsymbol{T}(\mathrm{Sec}) \\
\text { Operating time as per Arduino }\end{array}$ & 1 & 0.6 & 0.29 & 0.17 \\
\hline Operating time as per IEC (Sec) & 1 & 0.6 & 0.3 & 0.17 \\
\hline \% Error & 0 & 0 & 0.03 & 0 \\
\hline \hline
\end{tabular}

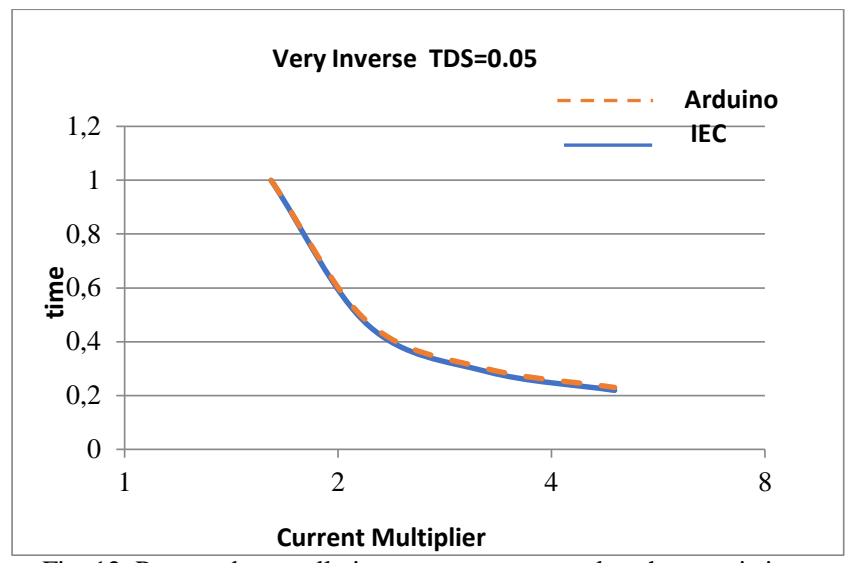

Fig. 12. Proposed normally inverse overcurrent relay characteristic at TDS $=0.05$ compared with IEC standard using simulator

\section{Scenario-3: Simulation of extremely inverse overcurrent relay}

This mode can be obtained by selecting the third mode "extremely invers". The typical schematic diagram for this mode is shown in Fig. 11. Similar to the above two scenarios, the extremely inverse overcurrent relay characteristic values are computed, tabulated and drawn. It can be observed from Fig. 14 that the proposed extremely inverse overcurrent relay characteristic is also coincide with the characteristics resulted from IEC standard with a very small errors explained by Table V.

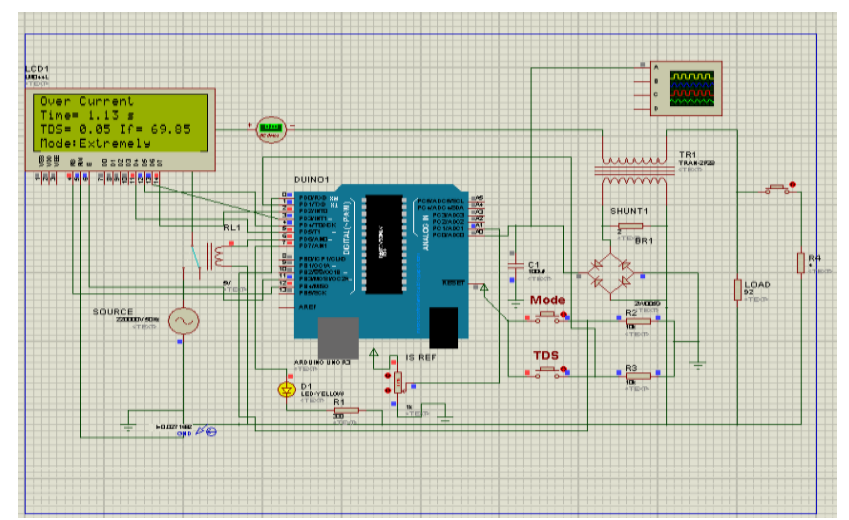

Fig. 13. Extremely characteristic of overcurrent relay at TDS equal 0.05

TABLE V: EXTREMELY INVERSE OVERCURRENT RELAY CHARACTERISTIC RESULTS AT TDS $=0.05$

\begin{tabular}{lllll}
\hline \hline $\boldsymbol{I}_{\boldsymbol{f}}(\mathrm{A})$ & 162 & 107 & 70 & 53 \\
\hline $\boldsymbol{I}_{\text {pickup }}(\mathrm{A})$ & 33 & 33 & 33 & 33 \\
\hline $\boldsymbol{M}=\frac{\boldsymbol{I}_{\boldsymbol{f}}}{\boldsymbol{I}_{\text {pickup }}}$ & 4.91 & 3.24 & 2.21 & 1.61 \\
\hline $\begin{array}{l}\boldsymbol{T} \text { (Sec) } \\
\text { Operating time as per Arduino }\end{array}$ & 0.17 & 0.42 & 1.13 & 2.42 \\
\hline Operating time as per IEC (Sec) & 0.18 & 0.43 & 1.13 & 2.42 \\
\hline$\%$ Error & 0.05 & 0.02 & 0 & 0 \\
\hline \hline
\end{tabular}

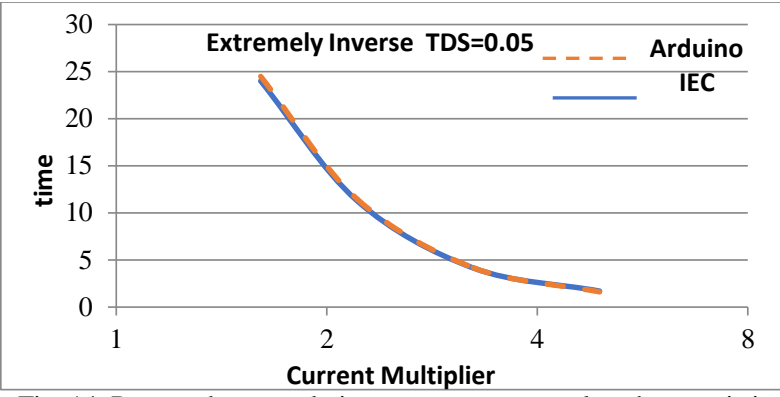

Fig. 14. Proposed extremely inverse overcurrent relay characteristic at TDS $=0.05$ compared with IEC standard using simulator

\section{PRACTICAL CiRCUIT IMPLEMENTATION}

A practical circuit implementation of the proposed overcurrent relay using Arduino Uno controller is shown in Fig. 5. For normally inverse overcurrent relay with $\mathrm{TDS}=1$, the circuit utilizes CT ratio with 500/1, shunt resistance "R1" (0-8.0 ohm) and motor with full load current 1.05 A.

The current sensed by the hall effect current transformer will produce voltage across shunt resistance which is converted to dc voltage and fed to Arduino Uno. This voltage is usually within 5 volts to suite the controller chip. According to the logic that has been programed to Arduino Uno, the sensed current is compared with the pre-set values in the controller. If the current greater than the trip set value (1.5 full load current $=1.5 * 1.05=1.575 \mathrm{~A})$, a trip signal is generated and the solid-state relay is tripped as a circuit breaker and opens the circuit. The fault current tripping time appears on the LCD. The fault level is changed by adjusting different values of R2 and the corresponding tripping times are recorded. The results are graphed in Fig. 15. and tabulated in Table VI. It can be noticed that no trip happens for the practical circuit when the loading is less than $150 \%$ which coincides with the IEC standard. Also, the practical circuit performance is nearly the same as the IEC standard when the fault level increases with very small percentage error as indicated in Table VI. Where: IL is the load current (A), IS is the CT secondary current (mA), Vard is the Arduino dc rms voltage, TIEC is the operating time as per IEC (sec), Tm is the Actual Measured Time (sec).

TABLE VI: PROPOSED PRACTICAL NORMALLY INVERSE OVERCURRENT RELAY CHARACTERISTICS

\begin{tabular}{llllllll}
\hline \hline $\mathrm{I}_{\mathrm{L}}$ & $\mathrm{I}_{\mathrm{S}}$ & $\mathrm{M}$ & $\mathrm{V}_{\text {ard }}$ & $\mathrm{T}_{\mathrm{IEC}}$ & $\mathrm{T}_{\mathrm{m}}$ & $\begin{array}{l}\text { Error } \\
\%\end{array}$ & Trip \\
\hline 1.05 & 2.10 & 1.333 & 0.740 & - & - & - & No \\
\hline 2.00 & 4.00 & 2.539 & 0.84 & 11.6 & 12 & 3.4 & Yes \\
\hline 2.10 & 4.20 & 2.667 & 0.787 & 11 & 11.4 & 3.6 & Yes \\
\hline 2.50 & 5.00 & 3.175 & 0.925 & 7 & 7.2 & 2.9 & Yes \\
\hline $\begin{array}{l}\text { (Locked } \\
\text { Rotor) }\end{array}$ & 8.00 & 5.079 & 3.4 & 1.9 & 1.7 & -10.5 & Yes \\
\hline \hline
\end{tabular}




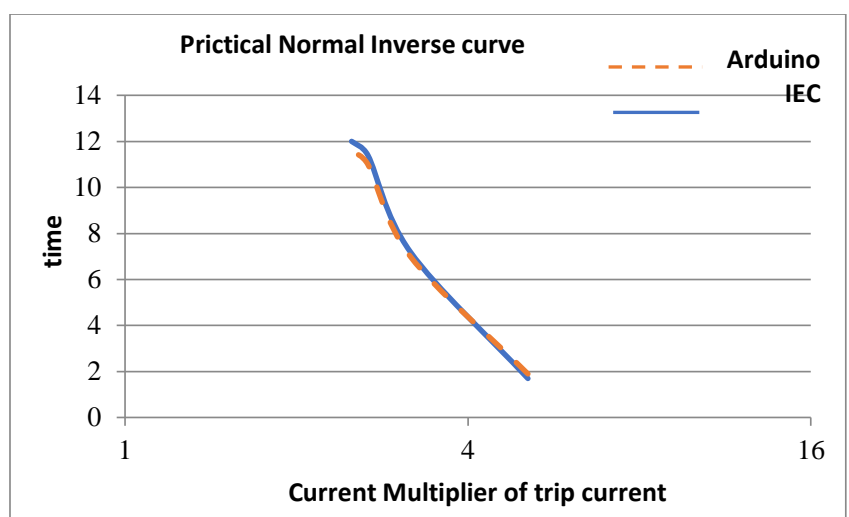

Fig. 15. Proposed very inverse overcurrent relay characteristic at TDS $=0.05$ compared with IEC standard using practical circuit

\section{CONCLUSION}

An Overcurrent relay was designed using Arduino Uno microcontroller. Software program has been created through Protos package using $\mathrm{C}$ language. To ensure the capability of the proposed overcurrent protection relay performance to a FREEDM system branch, software simulator and hard ware circuit has been developed. Software simulator has been formed to simulate normally inverse, very inverse and extremely inverse characteristics. A hardware circuit was fabricated using Arduino microcontroller board, uploaded with the created program and furnished with inputs and outputs to monitor and protect a motor load. Three overcurrent relay types have been applied to the software simulator and compared with the IEC 60255-151 standard behavior. The proposed relay characteristics nearly matched the standard ones. The error found between 1 to $4 \%$ for normally inverse, $3 \%$ for very inverse and 2 to $5 \%$ for extremely inverse. The normally inverse characteristics has been tested and verified using a practical circuit and error found between $3.4 \%$ to $-10.5 \%$ compared to the IEC 60255 151 standard.

\section{REFERENCES}

[1] A. Huang, "FREEDM System - A Vision for the Future Grid," IEEE Power and Energy Society General Meeting, Providence, USA, 25-29 July 2010, pp.1-4

[2] N Sharma, "Novel Directional Protection Scheme for the FREEDM Smart Grid System," M. Sc. Thesis submitted to Arizona State University, August 2015.

[3] https://www.freedm.ncsu.edu/

[4] P. Mandava,"Design and Development of Protection Schemes for FREEDM Smart Grid Systems," M. Sc. Thesis submitted to Arizona State University, December 2014.

[5] O. Vodyakho, et.al., "Solid-State Fault Isolation Devices: Application to Future Power Electronics-Based Distribution Systems," IET Electric Power Application, Vol. 5, Issue 6, July 2011, pp. 521 - 528.

[6] M.F.Kotb, M. El-Saadawi, E.H. El-Desouky, "Protection Coordination Optimization for Future Renewable Electric Energy Delivery and Management (FREEDM) System', Journal of Electrical Engineering JEE, USA, 6(2018), pp. 161 -176

[7] A. Agarwal, "Overcurrent Protection of Transformer by incorporating IDMT Function with the Help of Arduino Uno Microcontroller," International Research Journal of Engineering and Technology (IRJET) Vol.: 03, Issue: 05, May-2016, pp. 1753-1755
[8] S. Bhattacharya, et al. "A Novel Approach to Overvoltage and Overcurrent Protection of Simple Single Phase Two Terminal Arduino Uno," International Journal of Electrical Engineering, Volume 10, Number 1, 2017, pp. 97-110

[9] K.B. Trivedi, C. Vibhkar, R. Sardhara, 'Differential Protection of Transformer Using Arduino with GSM and Voice Circuit', International Journal of Novel Research and Development (IJNRD) Volume 2, Issue 4 April 2017, pp.95-100

[10] R.B. Pandhare, et. al. "Transformer Protection by Using Arduino with GSM Modem," International Journal of Research in Advent Technology (IJRAT), Special Issue National Conference "CONVERGENCE 2017", 09th April 2017, pp. 119- 123

[11] I. Sharma, T. Patel, D. Tailor,"Differential Protection of Transformer Using Arduino," International Journal of Innovative and Emerging Research in Engineering Volume 3, Issue 7, 2016

[12] S.N. Syed, S. Radhika, M.N.S. Rani, 'Differential Current Protection of Transformer Using Arduino with Voice Alert', International Journal of Innovations in Engineering and Technology (IJIET), Volume 6 Issue 2 December 2015 pp. 206-212

[13] A. Naseem, N. Alam, 'Protection of Distribution Transformer Using Arduino Platform', Science International, Volume: 27, Issue: 1, 2015 , pp. 403-406

[14] R. Waswani, A. Pawar, M. Deore, R. Patel, "Induction Motor Fault Detection, Protection and Speed Control Using Arduino," International Conference on Innovations in Information, Embedded and Communication Systems (ICIIECS), Coimbatore, India, 17-18 March 2017.

[15] A. Verma, S.L. Shimi, 'Arduino Based Low Cost Power Protection System' International Journal of Advance Research, Ideas and Innovations in Technology (IJARIIT), Volume: 2, Issue: 4, 2012, pp 1-7

[16] IEC 60255-151: "Measuring Relays and Protection Equipment- Part 151: Functional Requirements for Over/Under Current Protection", International Electrotechnical Commission, 2009.

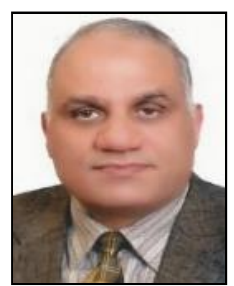

Mohamed F. Kotb was born in Monofia, Egypt, on 1960. He graduated from Mansoura University. He received M.Sc. and $\mathrm{PhD}$ Degree from Mansoura University in 1989 and 1998 respectively. He is a member of Electrical Department in faculty of Engineering, Mansoura University. He is interested in The Electrical Power System Analyses and application researches. He has wide experience with industry applications, consultations and Internationa Training. Dr. Mohamed is member in IEEE. His E mail is: mohamadfawzi@gmail.com.

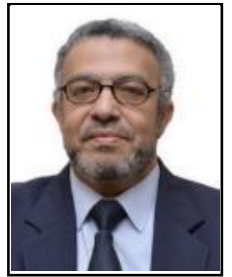

Magdi M. El-Saadawi was born in Mansoura, Egypt in 1959. He received his B.Sc. and M.Sc. from Mansoura University, Egypt in 1982 and 1988, respectively, and his $\mathrm{Ph} . \mathrm{D}$. from Warsaw University of Technology in 1997. He was a teaching assistant at El-Mansoura University from 1983-1992. From 1997, he was a staff member of the Electrica Engineering Department, Mansoura University, and has been a professor since May 2011. His fields of interest include, renewable energy, power system analysis, and AI applications in power systems. His e-mail is (m_saadawi@mans.edu.eg.

Eman H. El-Desouky received her B.Sc.in 2008 from Arab Academic for science and technology "AAST", department of electrical and control engineering. Also, completed her M.Sc. in 2015 from Electric department at faculty of engineering, Tanta university. She is interested in power system protection and control as well as renewable energy sources management. She is working in North Delta Electricity Distribution Co. Mansoura (Egypt). Her e-mail is (Eman.el desouky@ yahoo.com) 